Original Article

\title{
FORMULATION AND IN VITRO EVALUATION OF CURCUMIN LOADED JACKFRUIT SEED STARCH NANOPARTICLES
}

\author{
JUNMONI NATH \\ Department of Pharmaceutics, Girijananda Chowdhury Institute of Pharmaceutical Science, Azara, Guwahati-17 \\ Email: junmoninath2014@gmail.com
}

Received: 12 Jul 2020, Revised and Accepted: 08 Sep 2020

\section{ABSTRACT}

Objectives: To meet the above aim the following objectives are undertaken: (1) Isolation of starch from jackfruit seeds and formulation of curcumin loaded jackfruit seed starch nanoparticles (2) In vitro evaluations of the drug loaded nanoparticles

Methods: Jackfruit seed starch nanoparticles were prepared by Nanoprecipitation technique. In this technique, jackfruit seed starch was mixed with curcumin and acetone solution using a magnetic stirrer at $600 \mathrm{rpm}$. To the above solution, water were added dropwise and stirred at room temperature until acetone was completely vaporized. Nanoparticles were separated by centrifugation at $4000 \mathrm{rpm}$ after $40 \mathrm{~min}$.

Results: Particle size of prepared nanoparticle formulations was found to be 371 to $411.72 \mathrm{~nm}$ with PDI of 0.148 to 0.356 . The maximum \% drug entrapment was found to be $57.34 \%$ with formulation F5. In vitro release studies showed sustained release of drug till $12 \mathrm{~h}$.

Conclusion: The prepared nanoparticles were evaluated for its particle size, drug entrapment efficiency, in vitro drug release study, and surface morphology studies by scanning electron microscopy. The results of Fourier transform infrared studies of 1:1 physical mixture of drug and excipients confirmed the absence of incompatibility. Thus, the study concludes that curcumin loaded jackfruit seed starch nanoparticles were developed successfully by nanoprecipitation, which is expected to enhance the oral bioavailability of curcumin.

Keywords: Curcumin, Nanoparticles, Starch, Nanoprecipitation, In vitro drug release

(c) 2020 The Authors. Published by Innovare Academic Sciences Pvt Ltd. This is an open access article under the CC BY license (http://creativecommons.org/licenses/by/4.0/) DOI: http://dx.doi.org/10.22159/ijcpr.2020v12i6.40277. Journal homepage: https://innovareacademics.in/journals/index.php/ijcpr

\section{INTRODUCTION}

Nanoparticles are to be defined as a particulate dispersion or solid particles with a size range of 10-1000 nm. Nanoparticles can be divided into main two groups: nanospheres and nanocapsules. Nanospheres are considered as matrix particles whose entire mass are solid whereas nanocapsules are composed of a liquid or empty core surrounded by an organic solid shell. Nanospheres and nanocapsules are generally spherical but non-spherical shape can be encountered [1]. Polymeric nanoparticles plays a vital role in drug delivery as they generally increase the stability of any volatile pharmaceutical agents and that they are easily and cheaply fabricated in large quantities by a multitude of methods [2]. From among the polymers, biodegradable polymers like starch has received great attention in drug delivery applications as they are hydrophilic, biodegradable, versatile, inexpensive and biocompatible with tissue and cells. The major aim in designing nanoparticles as a delivery system are to achieve control particle size, surface properties and to release pharmacologically active agents to achieve the site-specific action of the drug at the therapeutically optimal rate and dose regimen [3].

Jackfruit is the name of the fruit from a jacktree (Artocarpus heterophyllus) that belongs to the Moraceae family. Jackfruit seeds contain considerably high amount of starch that qualify as a sustainable source of starch for food and pharmaceutical industries. Starch content in jackfruits seeds, as in other cultivars, depends of their structural composition, growing conditions, harvesting periods, and climates [4].

Curcumin is a phytopolylphenol pigment isolated from the plant Curcuma longa, commonly known as turmeric, with a variety of pharmacologic properties. Curcumin, has been the subject of several studies due to its known anti-cancer, antioxidant, anti-inflammatory, antimicrobial and antiviral activities [5-7]. Nevertheless, use of curcumin is hindered by its low water solubility, fast degradation, and low bioavailability [8]. Hence, there is a need for the development of new formulation for delivery, efficient loading, and sustained release of poorly water-soluble drug curcumin to increase its therapeutic efficacy and to decrease its side effects [9].
In this study, starch nanoparticles loaded with curcumin was prepared to improve the bioavailability of curcumin and was evaluated for its particle size and polydispersity index (PI), in vitro drug release, surface morphology by scanning electron microscopy (SEM) and drug-excipients compatibility studies by Fourier transform infrared (FT-IR).

\section{MATERIALS AND METHODS}

\section{Material}

Jackfruit seeds was bought from local market of Maligaon and starch was isolated, Curcumin from Ottokemi (Mumbai), Acetone from Merck Specialities Pvt. Ltd (Mumbai), Methanol Krishna Enterprise (Guwahati), Dialysis membrane from Sisco Research Laboratories Pvt. Ltd (Mumbai) and Sodium hydroxide from B S Trading (Kolkata). All other solvents and chemicals are of analytical grade.

\section{Methods of starch isolation}

\section{Sample preparation}

The seeds $(5 \mathrm{~kg}$ ) were clean and the white aril (seed coats) were peeled off. Seeds were then divided into two parts. One part was lyepeeled with $5 \% \mathrm{NaOH}$ for $2 \mathrm{~min}$ to remove the thin brown spermoderm covers the fleshly white cotyledons were come out. The seeds were then slice into thin chips ans was tray dried at $50 \mathrm{C}-60^{\circ} \mathrm{C}$ until their moisture content is less than $13 \%$. The chips were ground in a pin mill and then passed through 70 no mesh flour was packed in plastic pouches and stored in a refrigerator $\left(<5^{\circ}\right)$ until use [10].

\section{Starch isolation}

Starch isolation from flour was carried out by following the basic procedure washing steps. The flour was then mixed with 3 parts of distilled water and made into slurry. The slurry was filtered through a 70 no sieve to eliminate seed fibers. The starch suspension was allowed to settle and the liquid was decanted at $<10^{\circ} \mathrm{C}$. This step was repeated several times until the supernatant was clean and clear. The starch was then dried in a convection oven at $40{ }^{\circ} \mathrm{C}$ to $60{ }^{\circ} \mathrm{C}$ 
until the moisture content will be less than $13 \%$, then grind with the help of mortar and pastel and pass through a 70 no sieve. Sample will store in air tight container at room temperature until use [10].

\section{Preparation of jackfruit seed starch nanoparticles loaded with curcumin}

Preparation of jackfruit seed starch nanoparticles (JSSN) loaded with curcumin was performed as follows by Nanoprecipitation method with some modifications: 10-50 mg Jackfruit seed starch at different concentration was mixed with a curcumin/acetone solution $(10 \mathrm{mg}$ curcumin $/ 20 \mathrm{ml}$ acetone) during $15 \mathrm{~min}$ by using a magnetic stirrer at $600 \mathrm{rpm}$. The $20 \mathrm{ml}$ of water were added drop by drop with constant stirring. The resulting suspension was stirred at room temperature until acetone was completely vaporized. All experiments were carried out at $25{ }^{\circ} \mathrm{C}$. Nanoparticles were separated by centrifugation at $4000 \mathrm{rpm}$ during $40 \mathrm{~min}$; samples were washed several times with ethanol to remove any excess of curcumin. Finally, the curcumin-loaded nanoparticles were dried in hot air oven at $30^{\circ} \mathrm{C}$ during $48 \mathrm{~h} \mathrm{[11].}$

\section{Drug-excipient compatibility study by FT-IR}

This study was carried out to find out the compatibility between curcumin and different excipients to be used in formulations [7]. Physical mixture in ratio 1:1 of drug-excipients was prepared and scanned from $4000 \mathrm{~cm}-1$ to $400 \mathrm{ctd}$ in Bruker Alpha FT-IR spectrophotometer after placing the sample onto the sample holder. The spectra obtained were compared and interpreted for the functional group [11].

Characterization of prepared jackfruit seed starch nanoparticles

\section{Particle size and polydispersity Index}

To analyze particle size, each formulation of drug loaded lyophilized nanoparticles was dispersed in deionized water, centrifuged for $5 \mathrm{~min}$ at $5000 \mathrm{rpm}$ and filtered using $0.2 \mu \mathrm{m}$ membrane filter. Particle size and PI were determined by using Malvern Zetasizer Nano S90 at a temperature of $25^{\circ} \mathrm{C}$ at a measuring angle of $90^{\circ}$ to the incident beam [11].

\section{Entrapment efficiency}

Entrappment of Curcumin in starch nanoparticles were determined by extracting $5 \mathrm{mg}$ nanoparticles with $1 \mathrm{ml}$ acetone for $6 \mathrm{~h}$. From this solution $0.2 \mathrm{ml}$ was diluted with phosphate buffer $\mathrm{pH} 6.8$ and analyzed by UV spectrophotometer (Shimadzu UV-1800, Japan) at $421 \mathrm{~nm}$ against appropriate blank [11].

The entrapment efficiency was calculated using the following equation:

$$
\% \text { Entrapment efficiency }=\frac{\text { Weight of drug in nanoparticles }}{\text { Weight of drug in the formulation }} \times 100
$$

\section{SEM of nanoparticles}

The shape and surface characteristics of the nanoparticles were observed by SEM. The nanoparticle sample was thinly sprinkled onto a metal stub and vacuum coated with a thin layer of gold in an argon atmosphere. The SEM photomicrographs of the coated particles were obtained at $15 \mathrm{KV}$ using a ZEISS, Germany, SEM [11].

\section{In vitro drug release}

In vitro drug release was determined by Franz diffusion cell using Dialysis membrane where $20 \mathrm{mg}$ of jackfruit seed starch nanoparticles was diluted with 6.8 buffer solution and added to donor compartment. The content of the receptor media contained $250 \mathrm{ml}$ of buffer solution. At pre determine points (upto $12 \mathrm{~h}$ ), $5 \mathrm{ml}$ of the medium solution was withdrawn from the receptor compartment and replaced with the same amount of buffer solution, which was stirred continuously at $600 \mathrm{rpm}$ and maintained at $370{ }^{\circ} \mathrm{C}[12]$.

\section{RESULTS AND DISCUSSION}

\section{Drug-excipients compatibility study by FTIR}

The physical mixture of drug (curcumin) with polymer (Starch) clearly shows the retention of this characteristic peaks of Curcumin, thus revealing that there is no interaction between the selected drug and polymer.

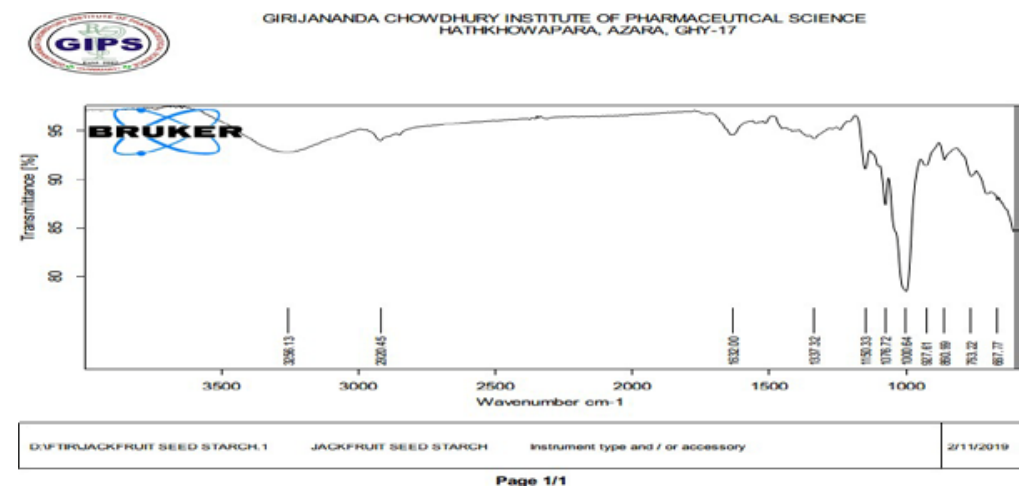

Fig. a: FTIR spectra of jackfruit seed starch

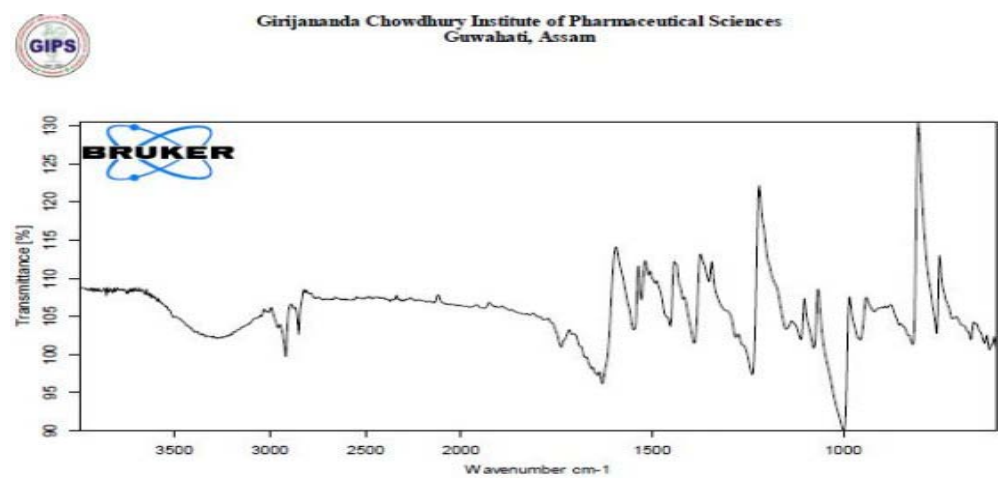

Fig. b: FTIR spectra of curcumin 


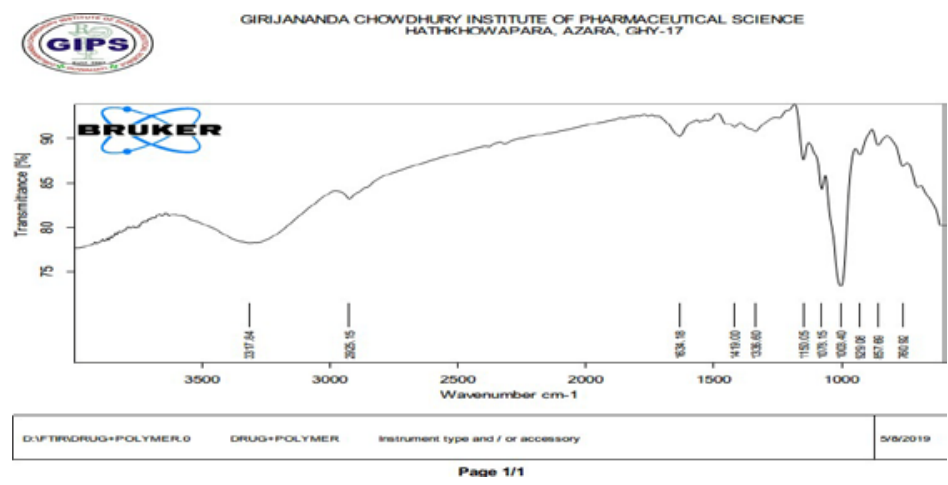

Fig. c: FTIR spectra of curcumin and starch

\section{Physicochemical characteristics}

The physicochemical characteristics of curcumin loaded jackfruit seed starch nanoparticles were briefly narrated in table 1 . The results showed that the particle size of the prepared nanoparticles varied from 371 to $411.72 \mathrm{~nm}$ with a low PI in the range of 0.148 to 0.356 as shown in table 1 . The PI was found to be $<0.5$, which is a considered as proof of a homogeneous nanoparticle formulation.

Table 1: Particle size and polydispersity index

\begin{tabular}{llll}
\hline Formulation code & Drug: polymer & Mean diameter (nm) & PDI \\
\hline F1 & $1: 1$ & 387.11 & 0.262 \\
F2 & $1: 2$ & 410.67 & 0.266 \\
F3 & $1: 3$ & 411.72 & 0.356 \\
F4 & $1: 4$ & 406.44 & 0.148 \\
F5 & $1: 5$ & 371 & 0.176 \\
\hline
\end{tabular}

\section{Entrapment efficiency}

The prepared nanoparticles showed entrapment efficiency in the range of $19 \%$ to $57 \%$ depending on the drug polymer ratio shown in table 2. The entrapment efficiency of nanoparticles increased with increase in polymer concentration. The low drug entrapment efficiency values indicate relatively low affinity of the drug with the polymer matrix

Table 2: Entrapment efficiency data for different formulations

\begin{tabular}{lll}
\hline Formulations & Drug: polymer (in wt) & \%Entrapment efficiency \\
\hline F1 & $1: 1$ & 19.32 \\
F2 & $1: 2$ & 31.14 \\
F3 & $1: 3$ & 44.72 \\
F4 & $1: 4$ & 51.22 \\
F5 & $1: 5$ & 57.34 \\
\hline
\end{tabular}

\section{In vitro drug release studies}

The in vitro drug release studies of nanoparticles were carried out at
$370 \pm 20^{\circ} \mathrm{C}$ in Phosphate buffer $\mathrm{pH} 6.8$ for a period of $12 \mathrm{~h}$ using dialysis bag technique. The drug release data of different formulations in Phosphate buffer pH 6.8 are given in table 3.

Table 3: In vitro drug release profiles of nanoparticles in phosphate buffer $\mathrm{pH} 6.8$

\begin{tabular}{|c|c|c|c|c|c|}
\hline \multirow[t]{2}{*}{ Time(h) } & \multicolumn{5}{|c|}{$\%$ Cumulative drug release } \\
\hline & F1 & F2 & F3 & F4 & F5 \\
\hline 1 & 2.12 & 2.56 & 3.62 & 3.77 & 4.99 \\
\hline 2 & 5.02 & 5.23 & 6.02 & 7.59 & 8.54 \\
\hline 3 & 9.77 & 9.99 & 9.59 & 9.99 & 11.69 \\
\hline 4 & 13.33 & 12.98 & 12.54 & 12.97 & 14.39 \\
\hline 5 & 16.65 & 15.97 & 16.66 & 17.03 & 18.78 \\
\hline 6 & 19.11 & 19.75 & 19.37 & 20.59 & 23.35 \\
\hline 7 & 21.04 & 22.23 & 22.66 & 23.54 & 25.41 \\
\hline 8 & 25.23 & 24.92 & 26.92 & 27.76 & 29.67 \\
\hline 9 & 27.61 & 27.88 & 28.22 & 30.54 & 32.39 \\
\hline 10 & 28.12 & 29.45 & 31.01 & 32.21 & 36.43 \\
\hline 11 & 30.43 & 31.21 & 32.34 & 34.54 & 38.89 \\
\hline 12 & 31.12 & 31.96 & 34.32 & 36.89 & 39.47 \\
\hline
\end{tabular}

Here sustained release of drug was observed from the formulation in phosphate buffer pH 6.8 for duration of $12 \mathrm{~h}$. Here we found that with increased in concentration of polymer in formulation drug release was sustained for long period, which may be due to the hydration capability 
of starch which on coming in contact with dissolution medium results to the formation of gelatinous mass that act as a retardant material for the drug to get diffused out. The cumulative \% drug release from formulation F1, F2, F3, F4 and F5 are 31.12\%, 31.96\%, 34.32\%, 36.89\% and $39.47 \%$ respectively. Amongst all the formulations, F5 formulation showed better sustained release profile of the drug for a period of $12 \mathrm{~h}$ in phosphate buffer $\mathrm{pH} 6.8$

\section{SEM}

The shape and surface characteristics of nanoparticles of optimised formulation (F5) was visualized using SEM, Zeiss, Germany. The SEM results are shown in fig. e.

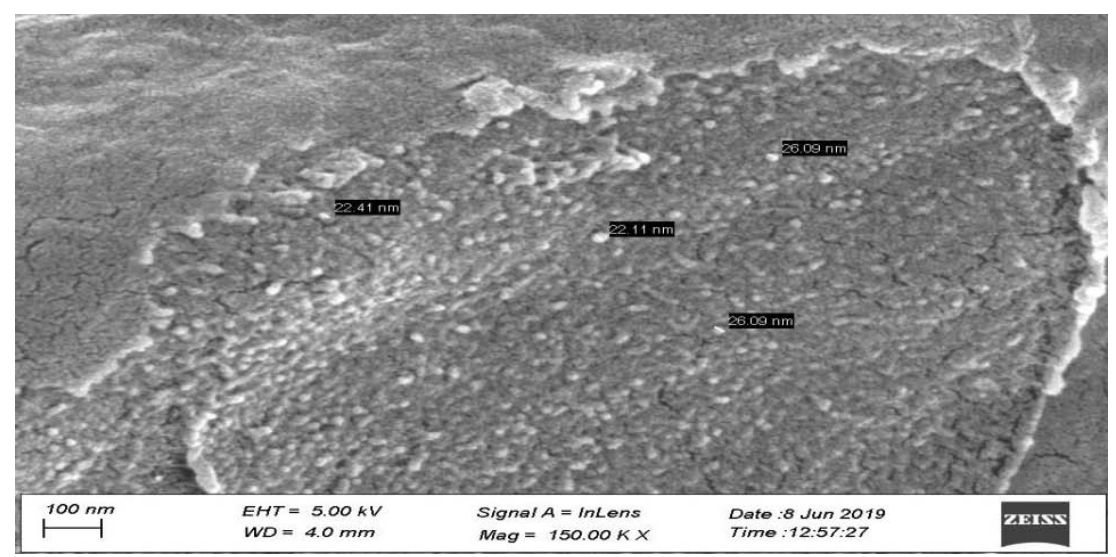

Fig. e: SEM of the formulation F5

\section{CONCLUSION}

In this study, Curcumin loaded jackfruit seed starch nanoparticles with particle size range between 371 to $411.72 \mathrm{~nm}$ were prepared successfully by nanoprecipitation technique. Nanoparticle size depends primarily on the excess of polymer added into the system and in vitro release study revealed the sustained release of drug for $12 \mathrm{~h}$. The FT-IR study results confirm the compatibility of Curcumin with the excipients used in formulations. Thus, the developed nanoparticles are expected to the improvement of the oral bioavailability of the drug.

\section{FUNDING}

Nil

\section{AUTHORS CONTRIBUTIONS}

All the authors have contributed equally.

\section{CONFLICT OF INTERESTS}

Declared none

\section{REFERENCES}

1. Langer R. Biomaterials in drug delivery and tissue engineering: one laboratory's experience. Accounts Chem Res 2000;33:94-101.

2. Dustgania A, Vasheghani Farahani E, Imani M. Preparation of chitosan nanoparticles loaded by dexamethasone sodium phosphate. Iranian J Pharm Sci 2008;4:111-4.

3. Bhadra D, Bhadra S, Jain P, Jain NK. Pegnology: a review of PEGylated systems. Pharmazie 2002;57:5-29.
4. Tulyathan V, Tananuwong K, Songjinda P, Jaiboon N. Some physicochemical properties of jackfruit (Artocarpus heterophyllus Lam) seed flour and starch. Sci Asia 2002;28:37-41.

5. Mai Z, Chen J, He T, Hu Y, Dong X, Zhang H, et al. Electrospray biodegradable microcapsules loaded with curcumin for drug delivery systems with high bioactivity. RSC Adv 2017;7:1724-34.

6. Mirzaei H, Shakeri A, Rashidi B, Jalili A, Banikazemi Z, Sahebkar A. Phytosomal curcumin: a review of pharmacokinetic, experimental and clinical studies. Biomed Pharmacother 2017;85:102-12.

7. Nelson KM, Dahlin JL, Bisson J, Graham J, Pauli GF, Walters MA. The essential medicinal chemistry of curcumin: miniperspective. J Med Chem 2017;60:1620-37.

8. Anand P, Kunnumakkara AB, Newman RA, Aggarwal BB. Bioavailability of curcumin: problems and promises. Mol Pharmaceutics 2007;4:807-18.

9. Zhao D, Zhao X, Zu Y, Li J, Zhang Y, Jiang R, Zhang Z. Preparation, characterization, and in vitro targeted delivery of folate-decorated paclitaxel-loaded bovine serum albumin nanoparticles. Int J Nanomed 2010;5:669.

10. Vazhacharickal PJ, Sajeshkumar NK, Mathew JJ, Albin AN. Morphological diversity of jackfruit (Artocarpus heterophyllus) varieties in Kerala. Prem Jose; 2018.

11. Chin SF, Mohd Yazid SN, Pang SC. Preparation and characterization of starch nanoparticles for controlled release of curcumin. Int J Polymer Sci 2014. https://doi.org/10.1155/2014/340121

12. Tan Y, Xu K, Li L, Liu C, Song C, Wang P. Fabrication of sizecontrolled starch-based nanospheres by nanoprecipitation. ACS Appl Mater Interfaces 2009;1:956-9. 